\section{Nexus efficiency of centralized and decentralized models for water management and food production in the region of Alentejo, Portugal}

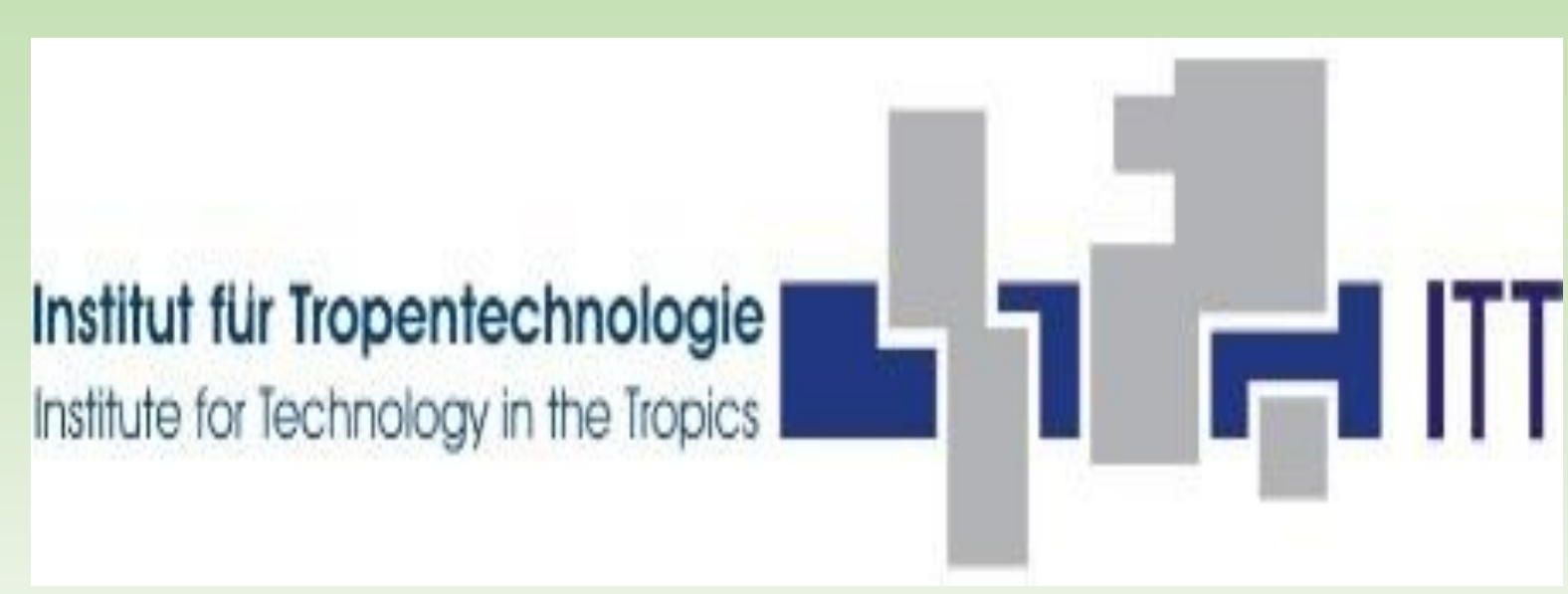

Technology Arts Sciences

TH Köln

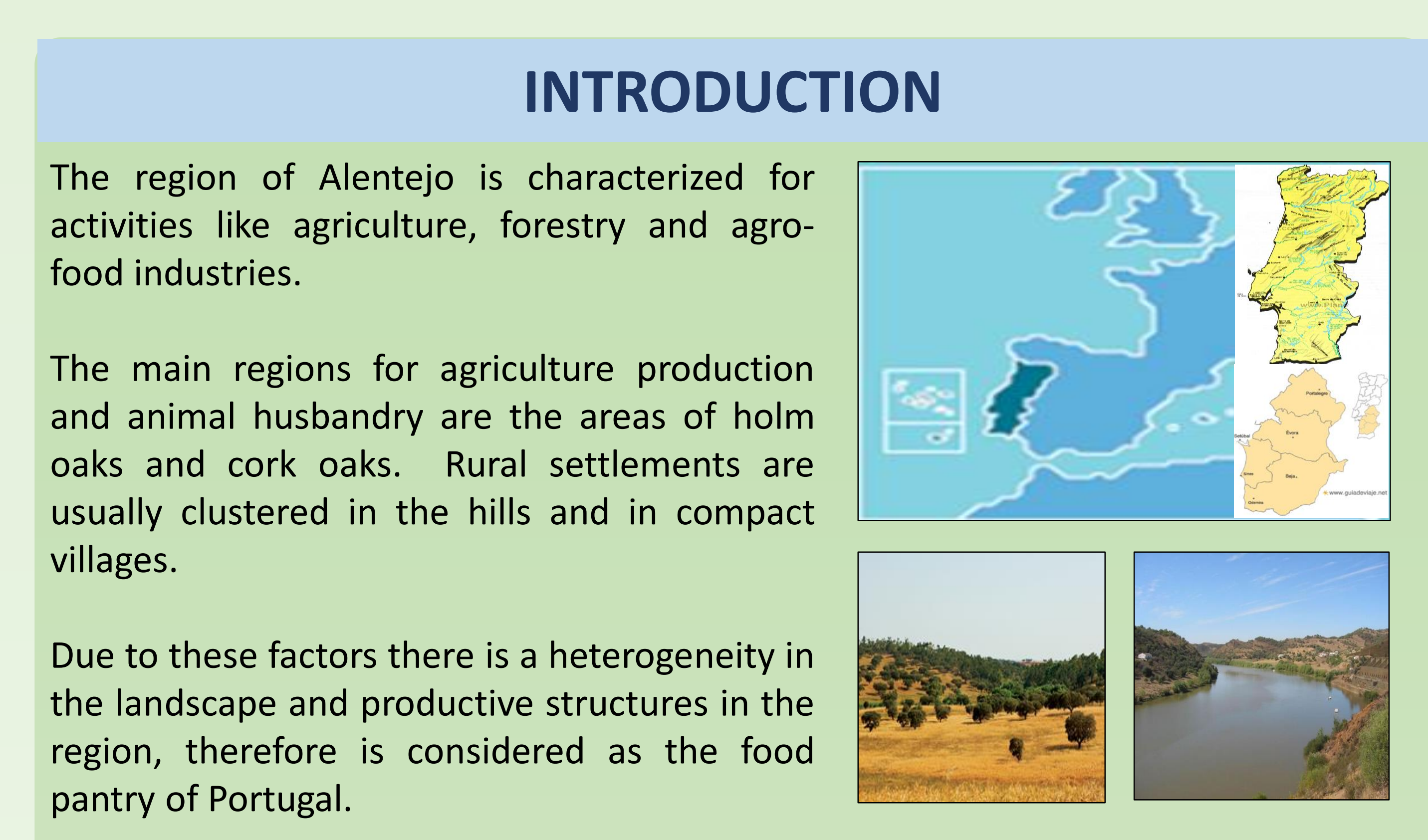

Food Production Agriculture products: vines, tomato, olive groves, wheat, sunflower and
forage oats.

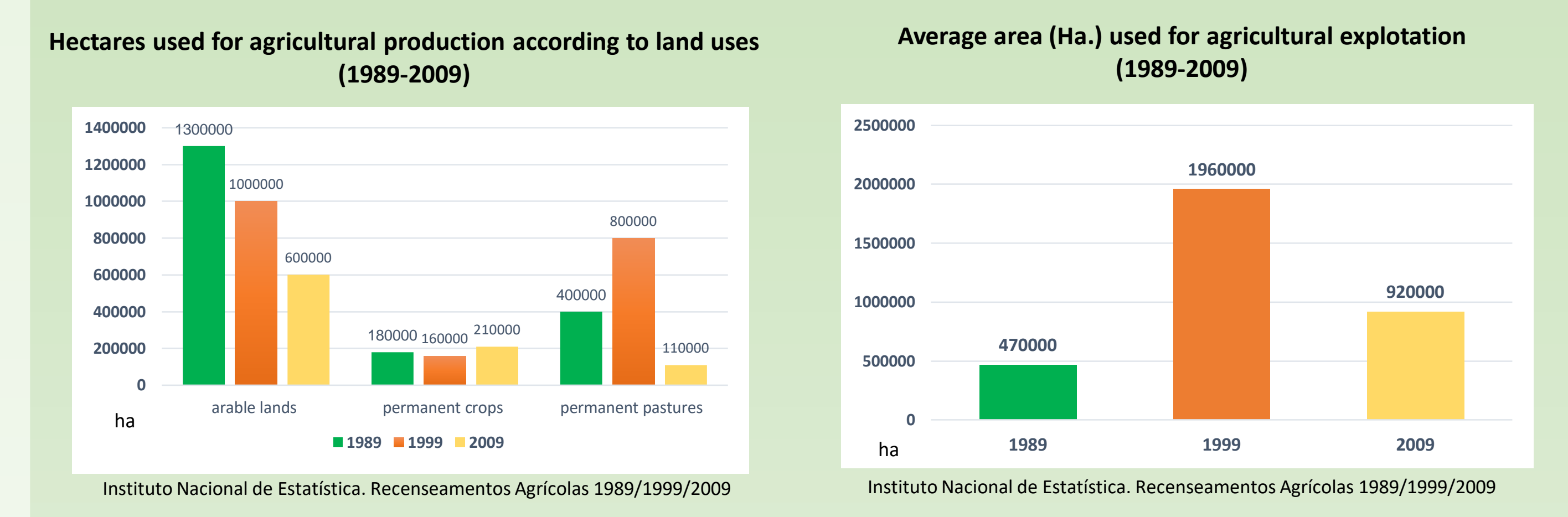

Water consumption

The Alqueva dam is the main source of water for agriculture $(124,585,745$ and is mainly fed by the Tejo and Guadiana rivers.

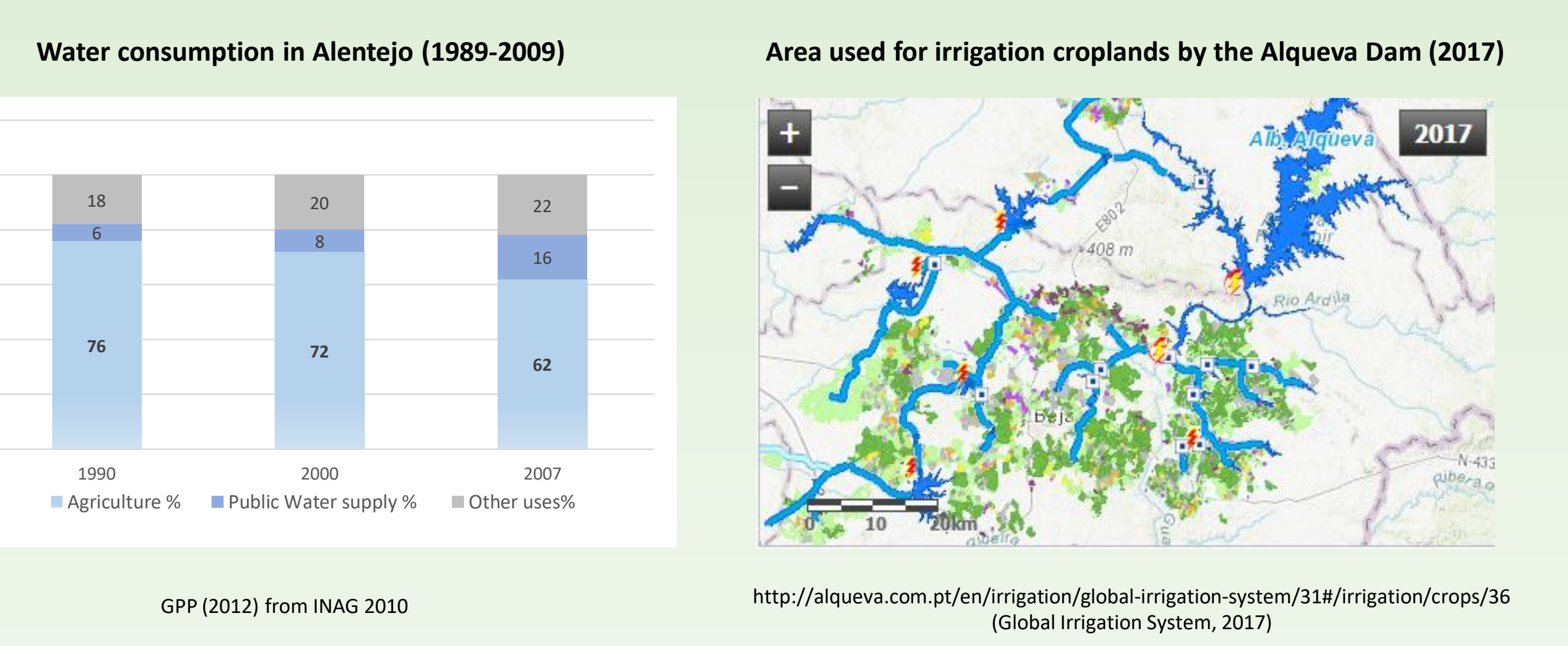

DESCRIPTION OF THE PROBLEM

The development of decentralized models for sustainable use of water for
agriculture has not been seen yet as a feasible solution to be implemented by agriculture has not been seen yet as a feasible solution to be implemented by governmental programs.

The Common Agriculture Policy (CAP) and current techniques of food southern Europe, so far the policies have not been able to improve the supply of water and ecosystemic services related.

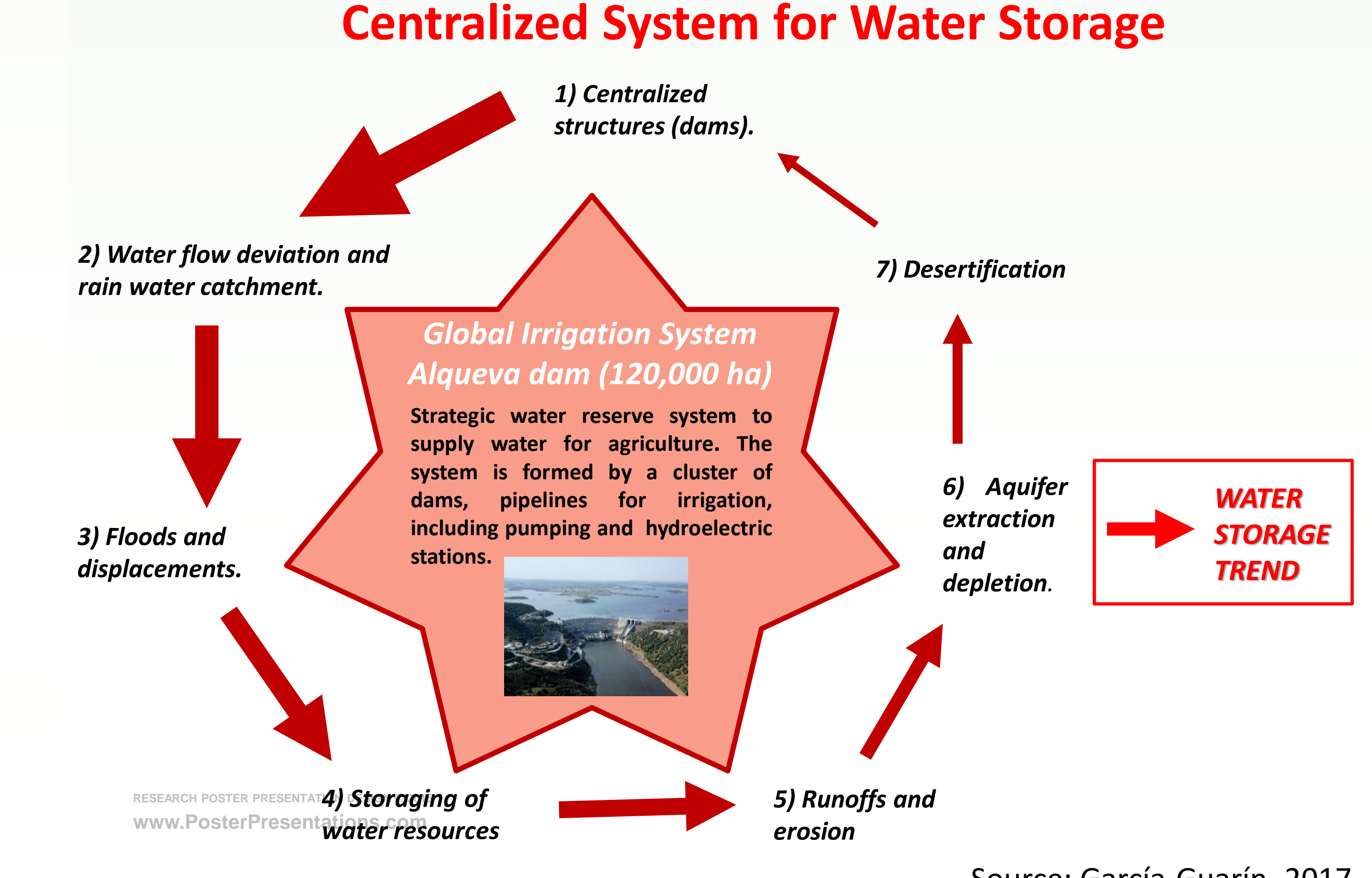

Decentralized System for

Water Reservoir

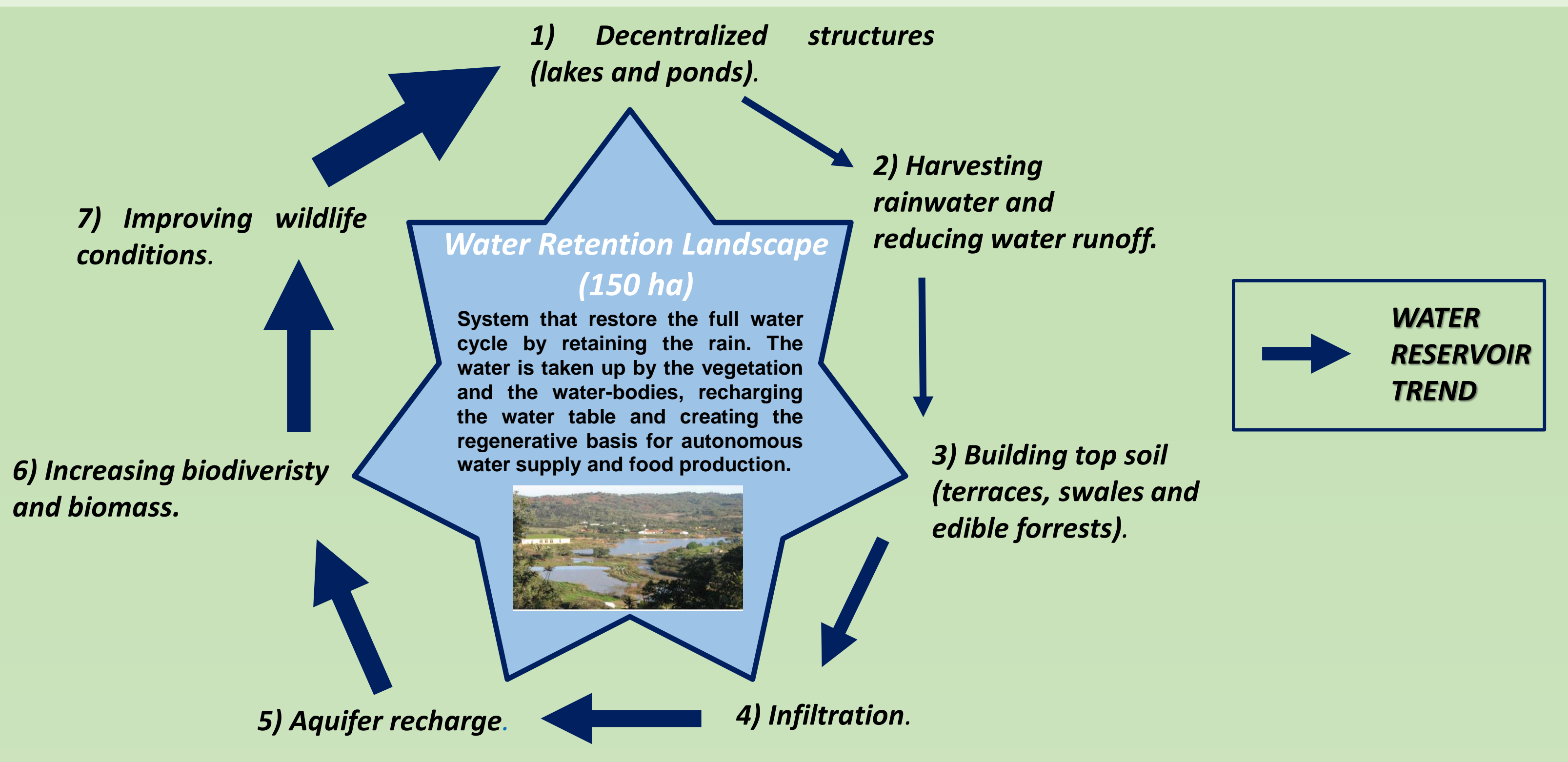

OBJECTIVES

General objective

Specific objectives

- To stress the importance of sustainable water management through
decentralized models such as water retention landscape (WRL) as a feasible assess how the efficiency of centralized and decentralized models of water
and food management contributes to the restoratition and regeneration of the
surffce layer of the soil vegetation cover and other ecosystem services decentralized models such as water retention landscape (WRL) as a feasible

- To showcase how ecological design is a sustainable long term solution for WATER \& FOOD NEXUS DIAGRAM (ALENTEJO REGION) SUSTAINABLE SUPPLY OF WATER

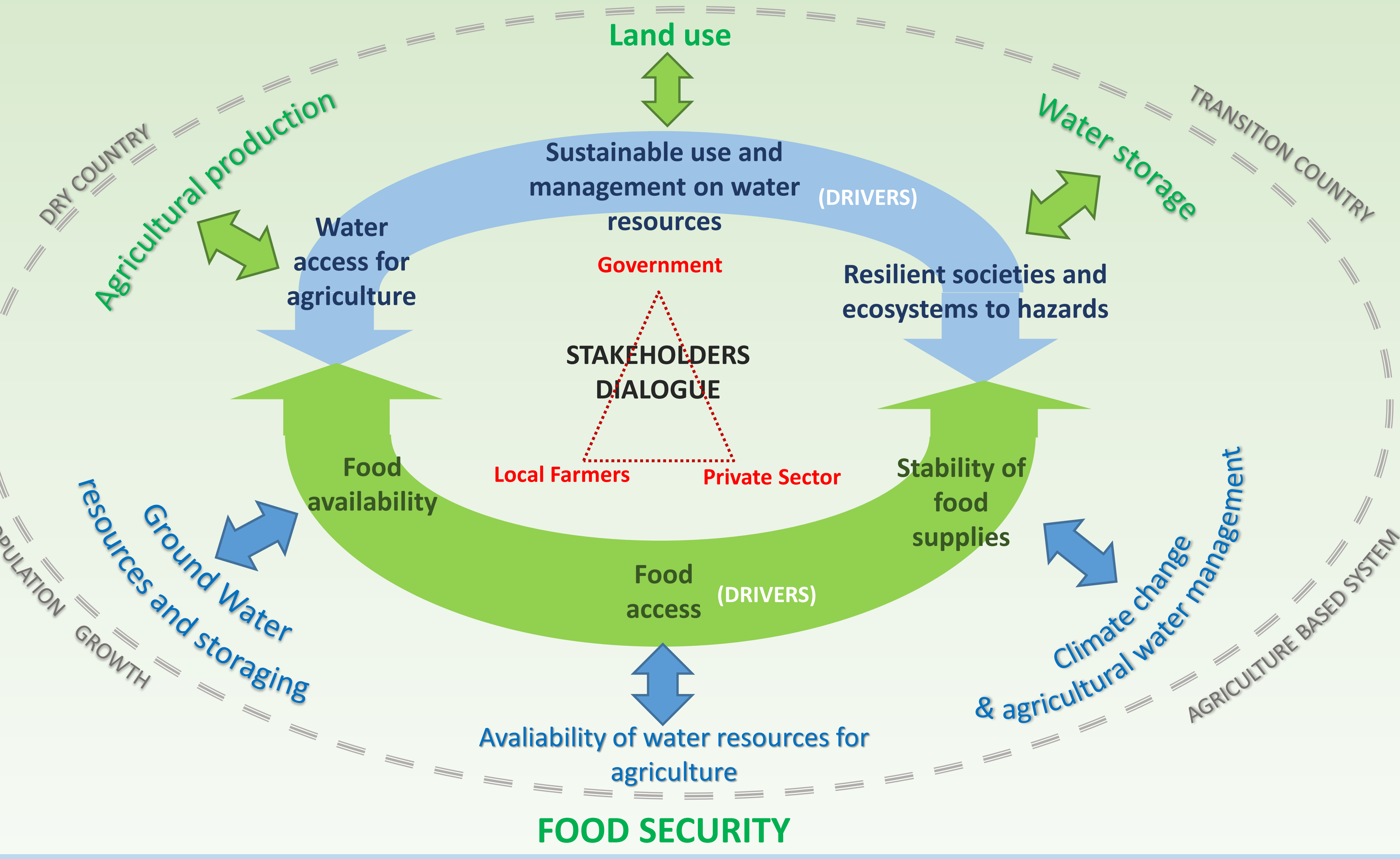

METHODS AND PROCEDURES

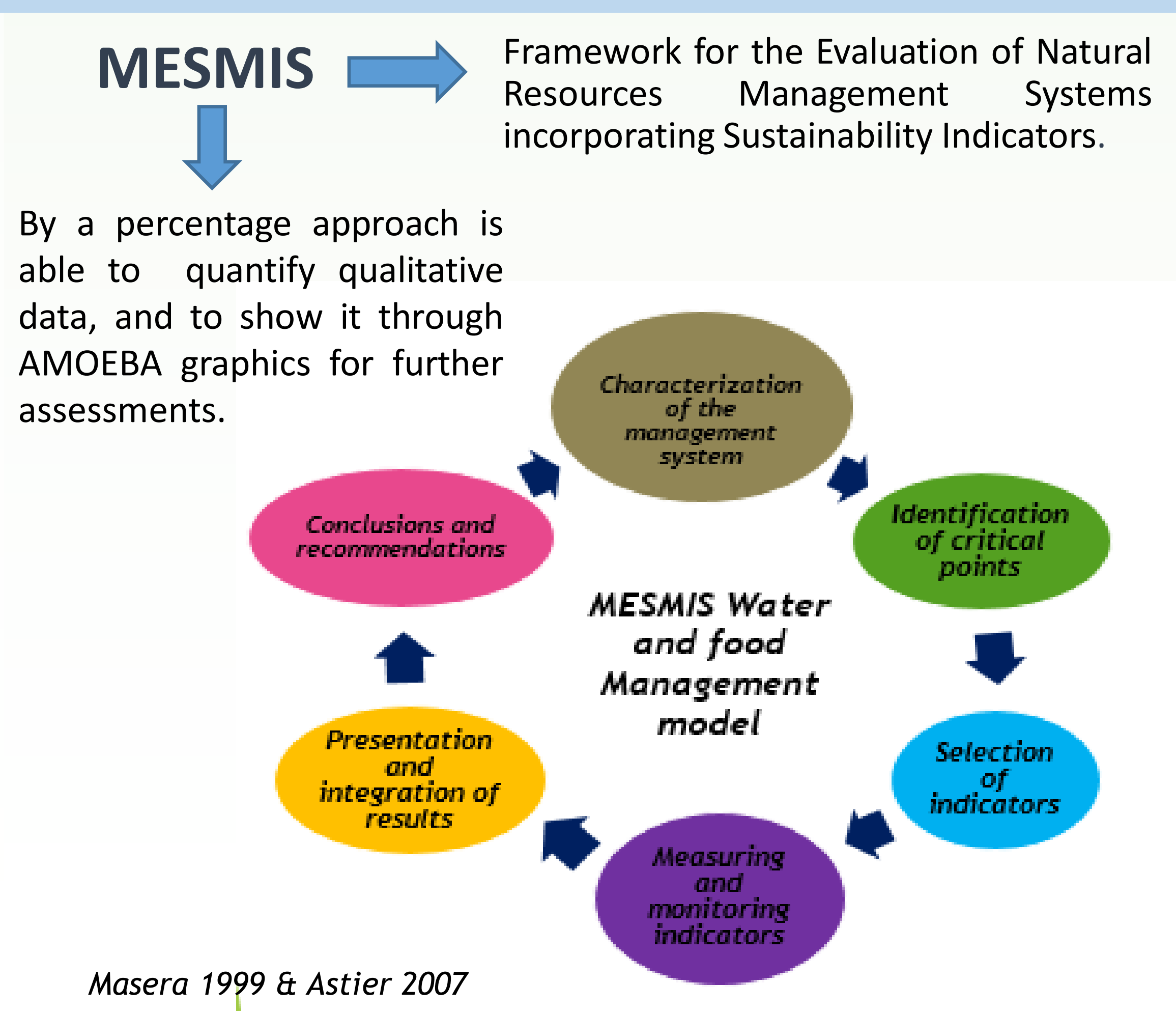

The diagram is framed by four socioeconomic characteristics that contributed to identify the main drivers considered for sustainable water assessment.

The double point arrows represents the Nexus an
analysis.

The triangle stress out the importance straight and equal communication as well as mutual support among the nvolved parties

Source: Garcia-Guarin, 2017

\begin{tabular}{|c|c|}
\hline ATTRIBUTES & SUSTENTABLITYY INDICATORS (\%) \\
\hline \multirow[t]{2}{*}{ Productivity } & $\begin{array}{l}\text { Cost investments among total population. } \\
\text { (1) }\end{array}$ \\
\hline & Cereal crops produced in the area. (2) \\
\hline \multirow[b]{2}{*}{ Equity } & Stakeholder's participation. (3) \\
\hline & $\begin{array}{l}\text { Satisfaction in decision making processes } \\
\text { between local authorities and } \\
\text { stakeholders. (4) }\end{array}$ \\
\hline \multirow[t]{2}{*}{$\begin{array}{l}\text { Stability and self- } \\
\text { management }\end{array}$} & $\begin{array}{l}\text { Water catchment for irrigation from the } \\
\text { region. (5) }\end{array}$ \\
\hline & Cultivated land for permanent crops. (6) \\
\hline
\end{tabular}

How to calculate them?

$$
\mathbf{P P}=\left[\frac{\mathrm{SS}}{\mathrm{TS}}\right] \mathbf{O P}
$$

$\mathrm{PP}=$ Performance Percentag

SS = Selected Sample

$O P=$ Optimal Percenta

$$
\text { Source: Garcí-Guarin, } 2017
$$

Indicator performance

$$
\left.\begin{array}{l}
81-100 \%: 5 \\
61-80 \%: 4 \\
41-60 \%: 3 \\
21-40 \%: 2
\end{array}\right] \begin{gathered}
\text { Indicator } \\
\text { values }
\end{gathered}
$$

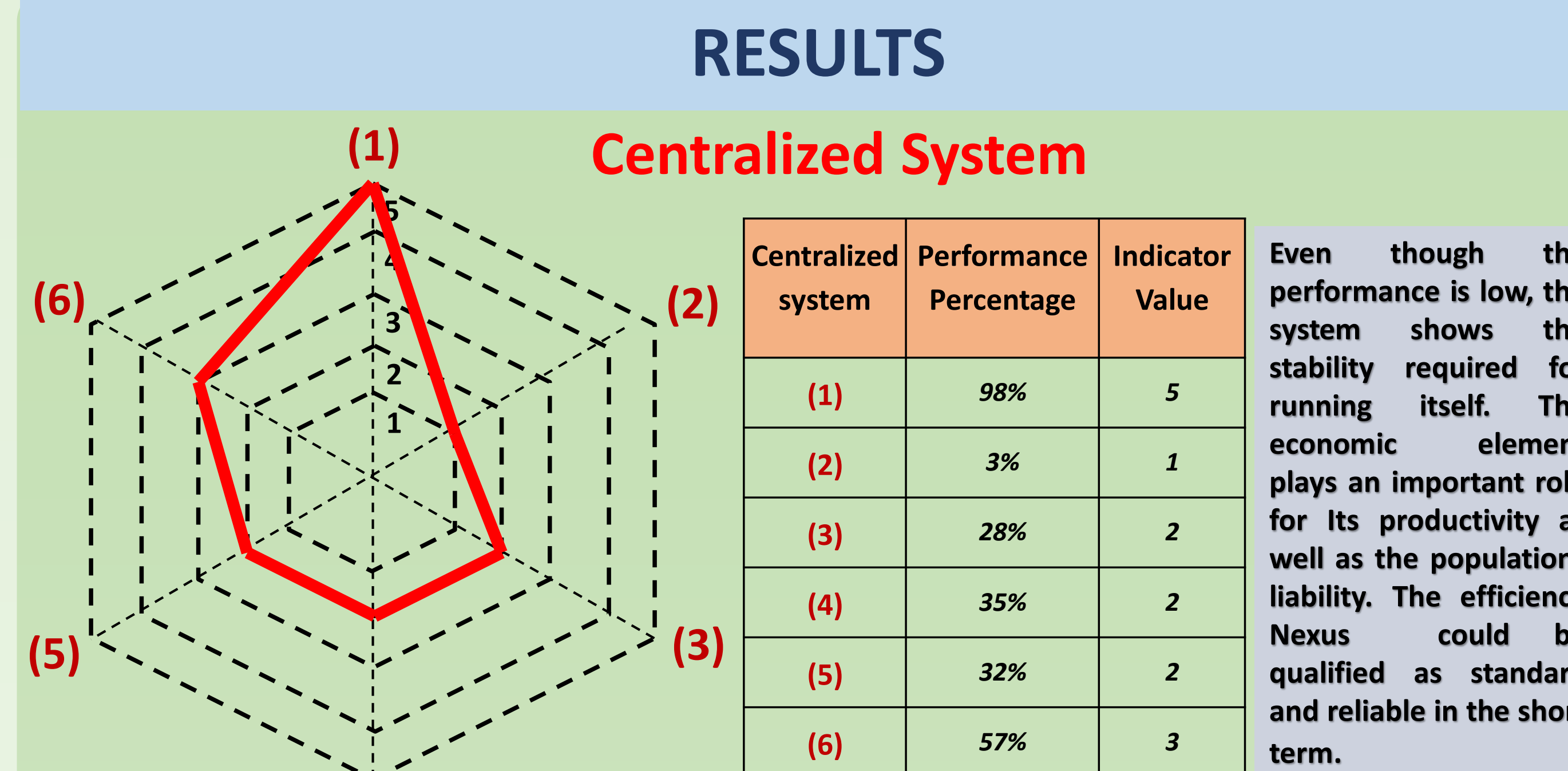

Decentralized System

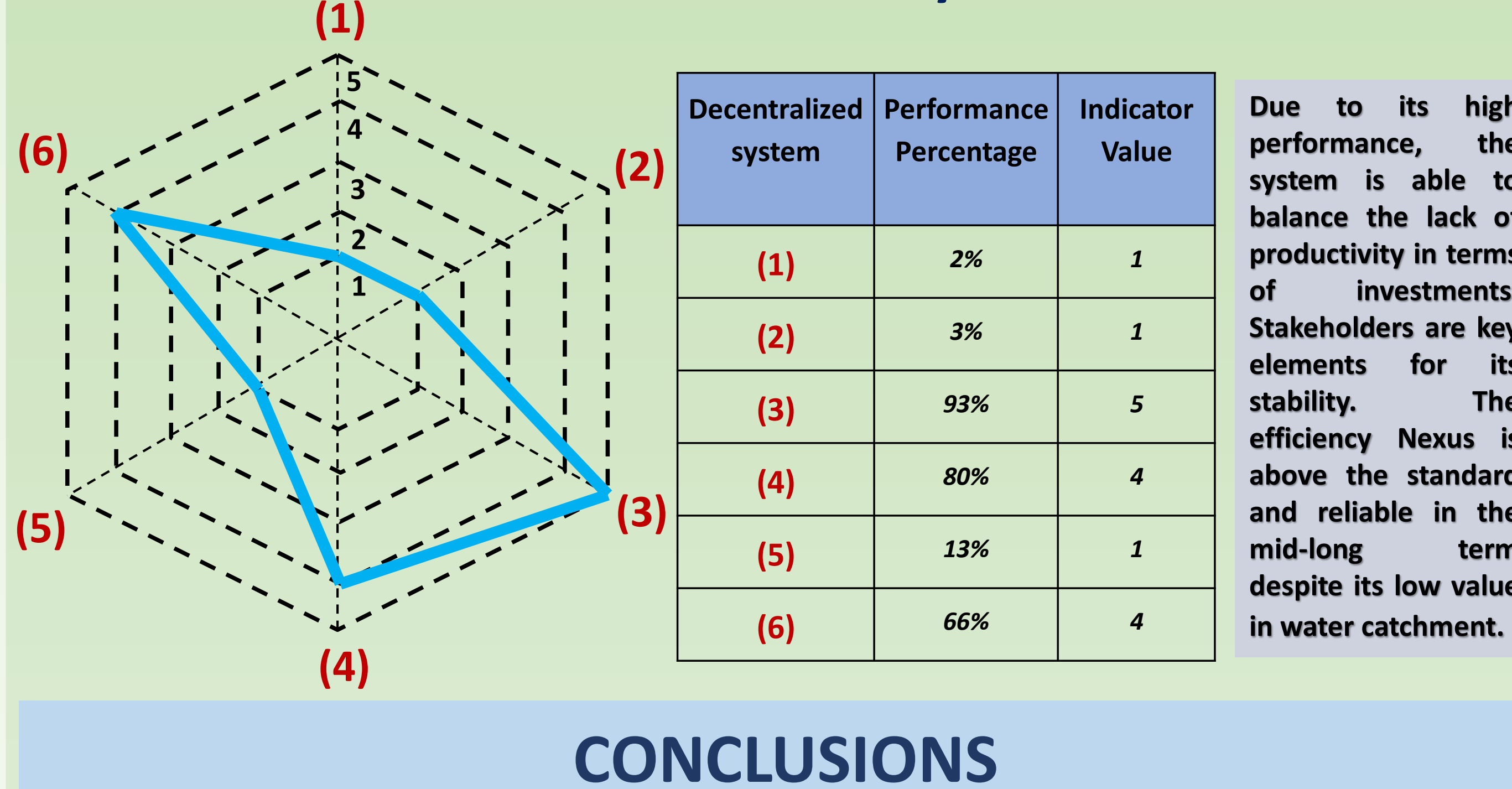

Considering the targets and aims of the analyzed systems the Nexus model is a reliable tool able to give the foundations to elaborate and evaluate precise indicators between water-food interactions.

The implementation of decentralized system for water reservoir, under the resources and food production can be achieved. On the other hand, how the nexus accelerate the restoration process of the ecosystems, contributing to the prevention of hazards in regions threatened by erosion and droughts.

The systemic approach of MESMIS methodology allows to analyze qualitative and decentralied models considering the emerging properties from the interaction between the subunits within the system.

Both approaches are feasible and efficient enough to maintain themselves alon from each system and to inter wate them to enhance each other performances and to improve the level of sustainability within the nexus.

\section{REFERENCES}

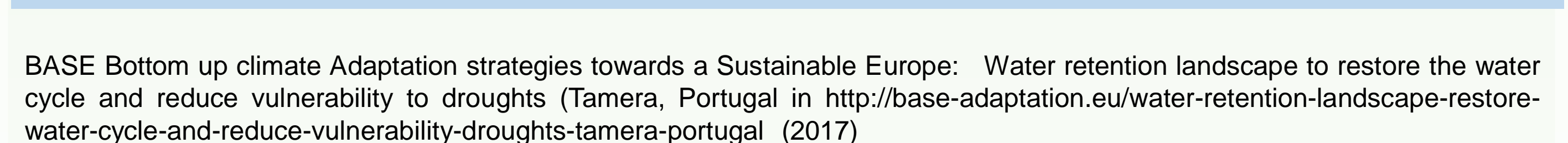

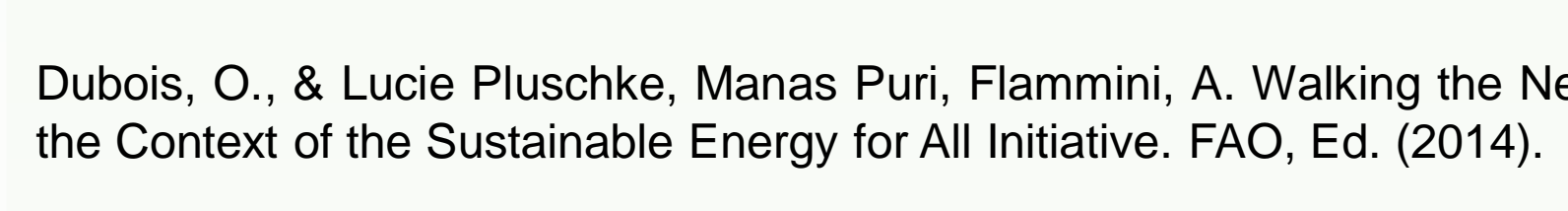

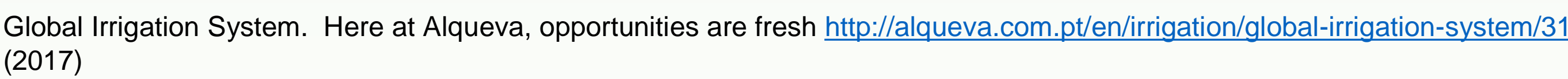

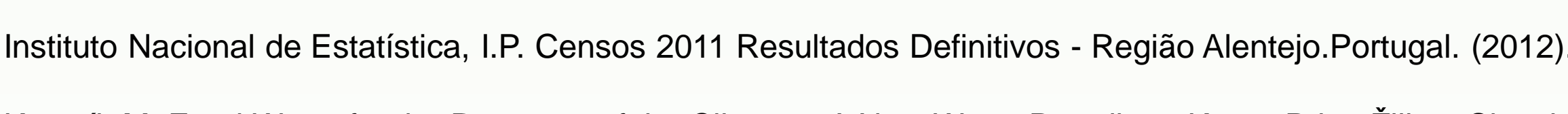

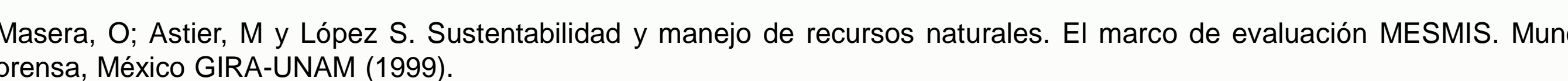

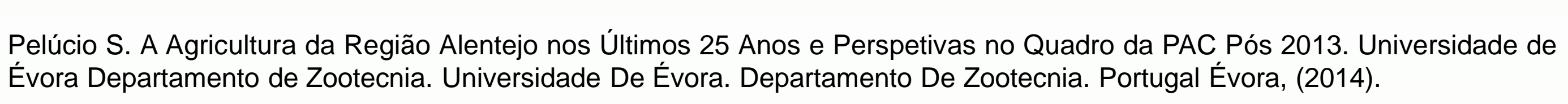

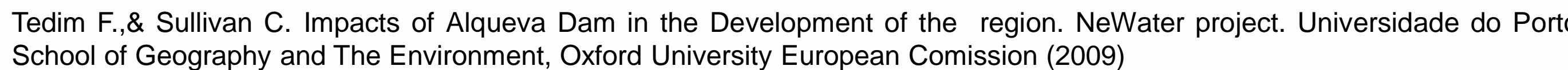

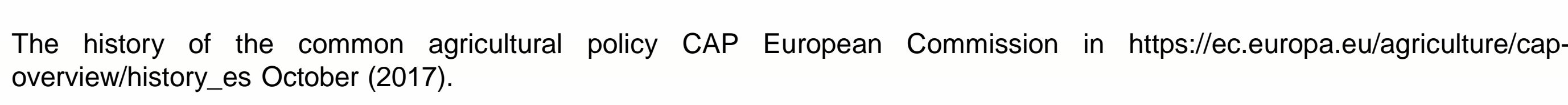

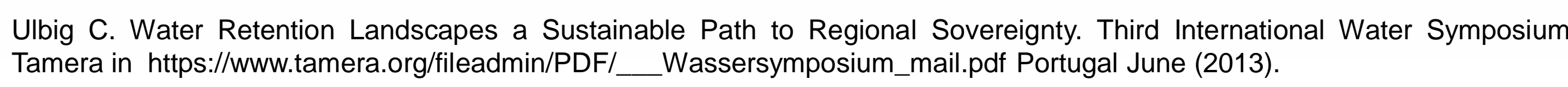

